\title{
Non-medical prescription stimulant use to improve academic performance among Australian university students: prevalence and correlates of use
}

\author{
Jayne Lucke ${ }^{1,2^{*}} \mathbb{D}$, Charmaine Jensen $^{3}$, Matthew Dunn $^{4,5}$, Gary Chan $^{3}$, Cynthia Forlini $^{6}$, Sharlene Kaye ${ }^{5}$, \\ Bradley Partridge ${ }^{7,8}$, Michael Farrell ${ }^{5}$, Eric Racine $e^{9}$ and Wayne Hall ${ }^{3}$
}

\begin{abstract}
Background: Some university students consume pharmaceutical stimulants without a medical prescription with the goal of improving their academic performance. The prevalence of this practice has been well documented in the US, but less so in other countries. The potential harms of using prescription stimulants require a better understanding of the prevalence of this practice within Australian universities.

Methods: An internet survey of 1136 Australian students was conducted in 2015 in three large Australian universities. Students were asked about their personal use of prescription stimulants, attitudes and experiences with prescription stimulants. They were also asked about their use of caffeine, energy drinks and illicit drugs to enhance their academic performance.

Results: Lifetime self-reported use of stimulant medication to improve academic performance was 6.5 , and $4.4 \%$ in the past year. Students were far more likely to report using coffee and energy drinks (41.4 and 23.6\% respectively, lifetime use) than prescription stimulants to help them study and complete university assessments. Non-medical use of prescription stimulants was strongly associated with a history of illicit drug use.
\end{abstract}

Conclusion: The prevalence of nonmedical prescription stimulant use to improve academic performance is low among university students in Australia, especially when compared with their use of coffee and energy drinks.

Keywords: Prescription stimulants, Cognitive enhancement, academic performance, Caffeine, University students, Australia, Prevalence, Correlates

\section{Background}

The increasing prescription of stimulant medications to treat Attention-Deficit Hyperactivity Disorder (ADHD) has led to concerns about the diversion and misuse of these medications by young people without a diagnosis of ADHD [1]. In particular, there has been considerable attention directed towards the non-medical use of prescription stimulants such as methylphenidate (Concerta,

\footnotetext{
* Correspondence: jlucke@latrobe.edu.au

${ }^{1}$ Australian Research Centre in Sex, Health and Society, School of Psychology and Public Health, College of Science, Health and Engineering, Building NR6, La Trobe University, Bundoora, VIC 3086, Australia

${ }^{2}$ School of Public Health, The University of Queensland, Herston, Brisbane,

QLD, Australia

Full list of author information is available at the end of the article
}

Ritalin), dextroamphetamine and amphetamine (Adderall) and modafinil (Modavigil) among North American college students as "study aids" to improve academic performance. Although relatively little is known about the prevalence of non-medical prescription stimulant use by Australian university students, there is some evidence that Australian university students use prescription stimulants non-medically as a way of coping with the demands of study $[2,3]$. Qualitative studies with Australian university students show that many are aware that some students use prescription stimulants as "study drugs" [4, 5]. The harms related to non-medical prescription stimulant use can be considerable [1], and it is therefore necessary to

(c) The Author(s). 2018 Open Access This article is distributed under the terms of the Creative Commons Attribution 4.0 International License (http://creativecommons.org/licenses/by/4.0/), which permits unrestricted use, distribution, and 
have an understanding of this important public health issue [6].

Recent findings from the US National Surveys on Drug Use and Health indicate that $6.6 \%$ of adults used prescription stimulants on average over a year, and of the small proportion of those who misuse stimulants (around 2\%) most do so to help them remain alert or concentrate [7]. While the problem of prescription stimulant misuse may not be significant in the general population, research suggests a high prevalence of diversion and misuse of prescription stimulants prescribed for ADHD in adolescent and young student populations $[1,8]$. There has been a particular focus on prescription stimulant misuse among students because of evidence that prescription stimulant misuse is higher in college students than among young people who do not attend college [9].

Much of the research on nonmedical prescription stimulant use among university students has come from the US, with studies including two recent reviews indicating a lifetime prevalence ranging from 5 to $43 \%$ [1012]. The wide variations in estimates of prevalence were attributable to different inclusion criteria and to methodological differences between the studies. However, national surveys of US college students have reported a prevalence of non-medical prescription stimulant use between 3 and 6\% [13-16]. A survey of 877 UK and Irish students in 2012 found that only $0.3-4 \%$ were regular past or current users of modafinil, methylphenidate or Adderall for cognitive enhancement and 10\% reported lifetime use [17]. These findings are similar to an Australian survey of 1729 university students which reported a lifetime prevalence $10.9 \%$ [3]. Other international studies have reported a higher prevalence of use, such as in Iceland (13\%) [18] and Puerto Rico (23.3\%) [19]. The range of prevalence reported internationally highlights the need to collect good Australian data as it is difficult to generalise from the results of studies in other countries.

There is a high prevalence of prescription stimulant use among those who drink alcohol [20] and those who frequently consume drugs [21]. Among young people dexamphetamine is seen as 'safe' because it is a pharmaceutical [22]. However, studies show that the most commonly reported motivation for prescription stimulant use among students is to help them concentrate and focus, and stay awake to complete assignments or study for exams [3, 18, 23-25]. Given reported prescription stimulant use among student groups, further information about the motivations for such use is needed to inform Australian policy and practice. The aim of this study was to investigate non-medical prescription stimulant use by Australian university students to improve academic performance, and specifically to report on the prevalence and correlates of prescription stimulant use for this purpose.

\section{Methods}

Students from three universities in Australia aged between 18 and 29 years were invited through targeted emails and university-based advertising to participate in an online survey in 2015 exploring substance use for academic improvement. Due to the requirements of the three universities it was not possible to send reminders to students who did not respond to the initial advertising or email invitation. The survey defined prescription stimulants to improve academic performance as "The non-medical use of prescription stimulants (such as Ritalin [methylphenidate], Adderall [dextroamphetamine] and modafinil [Provigil] without a prescription from a doctor) by students in an attempt to enhance their alertness, concentration, motivation or overall productivity." Participants were reminded where relevant that use of these drugs for recreational, medical or other non-study purposes did not count as use for improving academic performance. A direct hyperlink to the survey was posted on student association websites, degree or subject portals, or emailed.

The online survey was created with Checkbox Inc. Version 6.7. All data generated was stored securely with password protection. Each institution was provided with a unique URL link to their survey. Participants received an information sheet and provided written consent online before they could undertake the survey. Students who read the survey information sheet without completing the survey were considered an incomplete response. A survey response was considered complete only when the respondent clicked the "finish" button at the end of the survey. Participants could save and exit the survey at any time by closing their browser. Incentives were provided to increase student participation. Students could opt to participate in a prize-pool at the end of the survey consisting of $1 \times$ Apple iPad Air 16GB, 2×Apple iPad Minis $16 \mathrm{~GB}, 3 \times \$ 50$ Coles Myer vouchers, and $4 \times \$ 20$ Coles Myer vouchers. Prizes were drawn at the end of the academic semester. A random number generator was used to draw prize winners who met the inclusion criteria.

The online survey was constructed by the authors on the basis of previous research in this field, with particular attempts to address the limitations of previous surveys. The survey consisted of seven sections: i) demographics (e.g., age, sex, employment status); ii) education (e.g., years studying, study load, current Grade Point Average; discipline area); iii) suspected and diagnosed mental and physical health concerns (e.g., "Do you have any psychological health concerns? For example, anxiety, depression or attention deficit hyperactivity disorder"); iv) substance use 
for recreational purposes; v) attitudes toward the use of prescription stimulants to improve academic performance (e.g., "Students using prescription stimulants to help them study is acceptable" and "Prescription stimulants improve your study or academic performance"); vi) experiences with the use of prescription stimulants to improve academic performance (e.g., "Have you ever used substances to help you perform better at university? These substances may be anything from coffee or tobacco to prescription stimulants or street drugs used with the intention to help you study, work on assignments or take examinations"); and vii) substances used to improve academic performance consisting of over-the-counter products (e.g., coffee, energy drinks), prescription medication (modafinil, benzodiazepines), or illicit/street drugs (e.g., cocaine, ice).

IBM SPSS Statistics 23 software was used to generate descriptive statistics, frequencies, and means. The data was weighted by sex in order to represent the sex ratios for each participating university in accordance with each institution's 2015 student population numbers. Binary logistic regression was used to explore correlates of prescription stimulant use to improve academic performance that included age, sex, stimulant prescription, recreational illicit drug use, frequency of alcohol use and association with students who used prescription stimulants to improve academic performance. All variables were entered as one block in the model.

Ethical approval was obtained from the University of Queensland Behavioural and Social Sciences Ethical Review Committee (Approval Number: 2014001403). Permission was also granted for data collection at each participating university.

\section{Results}

\section{Characteristics of the sample}

A total of 2063 students viewed the survey. Of these 850 students viewed the information sheet but did not provide consent, 41 students provided consent but did not complete any survey items, and 34 responses were removed because the respondents were outside the specified age range. Two responses were also removed as they did not provide their sex and were not included in analyses weighted by sex. Therefore, the final sample comprised 1136 university students. The proportion of participants from each of the three participating universities were $24.4,37.6$, and $38.0 \%$. Compared to the university population in general the sample is slightly over representative of female students $(62.2 \%$ in this survey compared with $57.0 \%$ in the general student population) but had a similar proportion of international students (14.4\%) [26]. Sample characteristics and their association with prescription stimulant use are presented in Table 1 . Table 1 also shows the results of weighted analyses performed to examine the association between life time prescription stimulant use and sample characteristics. $P$-values were calculated based on designed based F-statistics.

Participants had a mean age of 21.29 years (SD 2.78). Most had completed one year or more of their studies, were completing their studies full-time, and were completing an undergraduate degree. Small proportions were off-campus/online students, living on campus, or international students. Approximately a fifth of the sample indicated that they had been diagnosed with a physical health condition and a fifth of the sample had a psychological health condition. Sixteen students indicated that they had prescriptions for stimulant medications. One-quarter $(25.9 \% ; n=286)$ of the sample reported that they had used an illicit drug for recreational purposes at some point.

\section{Prevalence of prescription stimulant use}

Overall, lifetime use of any prescription stimulant was $6.5 \%(n=74)$, with both past year use at $4.4 \%(n=50)$ and repeat use (more than 'once or twice only') at $4.7 \%$ $(n=53)$. Students reported the use of a number of prescription stimulants to improve academic performance, which are displayed across stimulant types and time in Table 2.

\section{Other substance use to improve academic performance}

Legally available substances that were also reportedly used to improve academic performance had a lifetime prevalence of $46.6 \%(n=529)$. The ten most commonly used legally available substances were: coffee $(41.4 \%, n=$ $470)$, tea $(25.9 \%, n=294)$, energy drinks $(23.6 \%, n=268)$, cola $(15.8 \%, n=179)$, caffeine pills $(9.1 \%, n=104)$, Omega 3 supplements $(7.4 \%, n=84)$, alcohol $(6.8 \%, n=$ $78)$, tobacco $(4.3 \%, n=49)$, cold and flu tablets $(4.0 \%, n$ $=46)$, and Gingko biloba $(3.1 \%, n=35)$. The lifetime use of illicit substances to improve academic performance was $2.8 \%(n=32)$ with the most commonly used substances being: cannabis $(1.5 \%, n=17)$, ice and speed $(0.6 \%, n=7)$ or $\operatorname{LSD}(0.5 \%, n=6)$.

\section{Correlates of prescription stimulant use to improve academic performance}

Binary logistic regression was used to examine the association between lifetime prescription stimulant use to improve academic performance and factors such as age, sex, and whether the participant had a prescription for stimulants, associated with other prescription stimulant users, frequency of alcohol use and history of illicit drug use. The factors that were associated with use of prescription stimulants to improve academic performance were: being male, $\mathrm{OR}=2.46,95 \% \mathrm{CI}[1.38,4.43]$, having a prescription for stimulants, $\mathrm{OR}=33.66,95 \%$ CI $[6.28$, 180.43], associating with other prescription stimulant 
Table 1 Sample characteristics and their association with prescription stimulant use $(N=1136)$

\begin{tabular}{|c|c|c|c|c|}
\hline & \multirow[b]{2}{*}{$\begin{array}{l}\text { Overall sample } \\
\text { (Unweighted descriptive) }\end{array}$} & \multicolumn{3}{|c|}{ Life time Prescription stimulant use (Weighted mean/ prevalence) } \\
\hline & & $\overline{\text { No }}$ & Yes & $p^{*}$ \\
\hline Characteristics & $\mathrm{M}(\mathrm{SD})$ & M & M & \\
\hline \multirow[t]{2}{*}{ Age } & $21.29(2.78)$ & 21.26 & 22.14 & .005 \\
\hline & $n(\%)$ & $\%$ & $\%$ & \\
\hline \multicolumn{5}{|l|}{ Sex } \\
\hline Female & $706(62.2)$ & 41.3 & 69.4 & $<.001$ \\
\hline Male & $430(37.8)$ & 58.7 & 30.6 & \\
\hline \multicolumn{5}{|l|}{ Residency } \\
\hline Australian citizen/resident & $969(85.6)$ & 85.5 & 84.1 & .753 \\
\hline Other & $163(14.4)$ & 14.5 & 15.9 & \\
\hline \multicolumn{5}{|l|}{ International student } \\
\hline Yes & $158(14.1)$ & 14.0 & 15.9 & .917 \\
\hline No & $964(85.9)$ & 86.0 & 84.1 & \\
\hline \multicolumn{5}{|l|}{ Study level } \\
\hline Undergraduate & $984(87.5)$ & 87.7 & 82.9 & .480 \\
\hline Graduate/ Post-graduate & $140(12.4)$ & 12.3 & 17.1 & \\
\hline Other & $1(0.1)$ & 0.0 & 0.0 & \\
\hline \multicolumn{5}{|l|}{ Highest level of parents education } \\
\hline High school or below & $253(22.4)$ & 21.7 & 25.2 & .588 \\
\hline Post-secondary school & $869(76.8)$ & 77.4 & 74.8 & \\
\hline Other & $10(0.8)$ & 0.9 & 0.0 & \\
\hline \multicolumn{5}{|l|}{ Hours of paid work during semester } \\
\hline Zero hours & $240(21.1)$ & 22.1 & 17.9 & .865 \\
\hline $1-25 h$ & $636(56.0)$ & 55.2 & 56.5 & \\
\hline$>25 h$ & $70(6.2)$ & 6.1 & 7.9 & \\
\hline Hours vary weekly & $73(6.4)$ & 6.5 & 5.3 & \\
\hline Do not work during semester & $117(10.3)$ & 10.1 & 12.4 & \\
\hline \multicolumn{5}{|l|}{ Years studying at university } \\
\hline Less than 1 year & $232(20.6)$ & 20.9 & 14.3 & .207 \\
\hline $1-3$ years & $455(40.5)$ & 40.6 & 34.5 & \\
\hline $3-5$ years & $329(29.3)$ & 29.2 & 37.8 & \\
\hline More than 5 years & $108(9.6)$ & 9.3 & 13.4 & \\
\hline \multicolumn{5}{|l|}{ Current study load } \\
\hline Full-time & $1033(92.0)$ & 92.0 & 91.9 & .943 \\
\hline Part-time & $81(7.2)$ & 7.2 & 7.0 & \\
\hline Withdrawn/ Deferred & $9(0.8)$ & 0.8 & 1.1 & \\
\hline \multicolumn{5}{|l|}{ Mode of study } \\
\hline On-campus & $1054(94.4)$ & 94.6 & 93.0 & .586 \\
\hline Off-campus/online student & $63(5.6)$ & 5.4 & 7.0 & \\
\hline \multicolumn{5}{|l|}{ Living on campus } \\
\hline Yes & $102(10.7)$ & 10.6 & 9.8 & .858 \\
\hline No & $849(89.3)$ & 89.4 & 90.2 & \\
\hline
\end{tabular}

Current Grade Point Average (GPA) 
Table 1 Sample characteristics and their association with prescription stimulant use $(N=1136)$ (Continued)

\begin{tabular}{|c|c|c|c|c|}
\hline \multirow{2}{*}{\multicolumn{2}{|c|}{$\begin{array}{l}\text { Overall sample } \\
\text { (Unweighted descriptive) }\end{array}$}} & \multicolumn{3}{|c|}{ Life time Prescription stimulant use (Weighted mean/ prevalence) } \\
\hline & & No & Yes & $p^{*}$ \\
\hline Fail & $16(1.4)$ & 1.4 & 4.3 & .215 \\
\hline Pass (4.0-4.9) & $168(15.0)$ & 15.2 & 18.7 & \\
\hline Credit (5.0-5.9) & $416(37.0)$ & 37.2 & 31.1 & \\
\hline Distinction (6.0-6.9) & $376(33.4)$ & 32.7 & 38.9 & \\
\hline High Distinction (7.0) & $92(8.2)$ & 8.4 & 4.0 & \\
\hline Other & $56(5.0)$ & 5.1 & 3.0 & \\
\hline \multicolumn{5}{|c|}{ Physical health problem diagnosis } \\
\hline Yes & $198(17.4)$ & 16.9 & 17.8 & .428 \\
\hline No & $938(82.6)$ & 83.1 & 82.2 & \\
\hline \multicolumn{5}{|c|}{ Mental health problem diagnosis } \\
\hline Yes & $227(20.4)$ & 19.0 & 32.1 & .064 \\
\hline No & $887(79.6)$ & 81.0 & 67.9 & \\
\hline \multicolumn{5}{|c|}{ Prescription for pharmaceutical stimulants } \\
\hline Yes & $16(1.4)$ & 0.8 & 11.8 & $<.001$ \\
\hline No & 1094 (98.6) & 99.2 & 88.2 & \\
\hline \multicolumn{5}{|l|}{ Previous illicit drug use } \\
\hline Yes & $286(25.9)$ & 22.9 & 77.5 & $<.001$ \\
\hline No & $818(74.1)$ & 77.1 & 22.5 & \\
\hline \multicolumn{5}{|l|}{ Frequency of alcohol use } \\
\hline Never/ Less than yearly & $237(21.5)$ & 22.4 & 7.7 & $<.001$ \\
\hline Yearly & $228(20.6)$ & 20.9 & 10.9 & \\
\hline Monthly & $365(33.0)$ & 32.7 & 39.0 & \\
\hline Weekly or more frequent & $275(24.9)$ & 24.0 & 42.4 & \\
\hline \multicolumn{5}{|c|}{ Peer use of prescription stimulants to improve academic performance } \\
\hline Yes & 369 (34.8) & 32.1 & 81.8 & $<.001$ \\
\hline No & $691(65.2)$ & 67.9 & 18.2 & \\
\hline
\end{tabular}

*Weighted analyses were performed to examine the association between life time prescription stimulant use and sample characteristics. $P$-values were calculated based on designed based F-statistics

users, $\mathrm{OR}=4.25,95 \% \mathrm{CI}[2.19,8.25]$, and previous illicit recreational drug use, $\mathrm{OR}=7.99,95 \%$ CI $[3.80,16.79]$. Age and frequency of alcohol use were not significantly associated with the use of prescription stimulants to improve academic performance.

\section{Discussion}

Contrary to reports that use of 'study drugs' is high [23], this study showed that both lifetime and recent use of prescription stimulants to improve academic performance was not common among Australian university

Table 2 Weighted prevalence of prescription stimulant use to improve academic performance

\begin{tabular}{lllllll}
\hline $\begin{array}{l}\text { Prescription } \\
\text { stimulant }\end{array}$ & $\begin{array}{l}\text { Lifetime } \\
\text { Use n (\%) }\end{array}$ & $\begin{array}{l}\text { Past Year } \\
\text { Use n (\%) }\end{array}$ & Past 6 months n (\%) & Past 3 months n (\%) & Past Month n (\%) & Past Week n (\%) \\
\hline Modafinil & $30(2.7 \%)$ & $27(2.3 \%)$ & $23(2.0 \%)$ & $21(1.8 \%)$ & $17(1.5 \%)$ & $12(1.0 \%)$ \\
Adderall & $33(2.9 \%)$ & $19(1.6 \%)$ & $16(1.4 \%)$ & $13(1.2 \%)$ & $11(1.0 \%)$ & $5(0.4 \%)$ \\
Concerta/Ritalin & $29(2.6 \%)$ & $16(1.5 \%)$ & $12(1.1 \%)$ & $7(0.6 \%)$ & $10(0.9 \%)$ & $9(0.8 \%)$ \\
Racetams & $14(1.2 \%)$ & $9(0.8 \%)$ & $7(0.6 \%)$ & $0(0.0 \%)$ & $0(0.5 \%)$ & $3(0.3 \%)$ \\
Atomoxetine & $1(0.1 \%)$ & $0(0.0 \%)$ & $0(0.0 \%)$ & $1(0.1 \%)$ & $1(0.01 \%)$ & $0(0.0 \%)$ \\
Phentermine & $1(0.1 \%)$ & $1(0.1 \%)$ & $1(0.1 \%)$ & & & $1(0.1 \%)$ \\
\hline
\end{tabular}


students. Use was unsurprisingly higher among those with a prescription for stimulants, among those who associated with others who used prescription stimulants to improve their academic performance, and among male students.

These findings are important because they confirm the importance of access to prescription stimulants for use, whether this is through the ability to arrange a prescription for oneself, or via social networks. This is in keeping with other international studies $[15,17]$. Another important finding was that non-medical use of prescription stimulants was strongly associated with a history of illicit drug use, and this is also consistent with previous international research [13, 15]. Neither age or alcohol use was associated with non-medical use of prescription stimulants to improve academic performance and these findings differ from previous US [20] and UK [17] studies that have shown alcohol use to be important, perhaps because the legal drinking age is 21 years in the US. This underscores the importance of country-specific studies. Another difference between US and Australia is the absence of the Greek system of sorority and fraternity houses in Australia. Membership of a sorority or fraternity house has been found to be associated with higher rates of non-medical use of prescription stimulants for academic purposes, particularly among males $[9,17]$. The present study found that males were more likely to be users of prescription stimulants, but those living on campus were no more likely to do so than those living off campus. Self-reported Grade Point Average and health problems were also not associated with prescription stimulant use. These findings are consistent with previous longitudinal research showing no significant change over time in Grade Point Average among students who used prescription stimulants for nonmedical purposes but a significant increase among students who did not [27]. These results support the recommendation that prevention and intervention strategies should emphasise the lack of evidence for claims of academic benefits from non-medical use of prescription stimulants.

Prevalence estimates have varied widely between countries. In the current study, the prevalence of non-medical prescription stimulants use for study purposes was lower than other Australian [3] and international studies [10, 11]. However, in accordance with previous research, non-medical prescription stimulant use was a small fraction of the use of other legally available substances such as caffeine and energy drinks. This suggests that the focus on prescription stimulant use may be diverting attention from other potentially risky substance use by students to improve their academic performance. It also highlights the importance of not exaggerating the use of prescription stimulants for academic improvement as a common practice $[28,29]$.
There are a number of limitations that should be considered in interpreting the results of this study. The cross-sectional design means that it is not possible to infer causal relationships between the use of prescription stimulants and other factors. The use of self-report measures may have introduced recall and social desirability biases. The recruitment method may have introduced selection bias whereby students who were using prescription stimulants or illicit drugs were less likely to participate. Another limitation of the study is the non-representative sample due to the reliance on a convenience sample of students. Universities are increasingly regulating student surveys online, given the many surveys students are already asked to complete (e.g., evaluations of teaching) so population surveys of university students are difficult to conduct. The study also relied on participants to make the distinction between use of prescription stimulants for study purposes and use for recreational or other purposes but the survey explicitly reminded participants of the distinction. Surveys in other student populations have been subject to similar limitations and biases. It is also important to note that our sample included both undergraduate and postgraduate students within the age range. There were too few postgraduates to analyse differences between undergraduates and postgraduates in prescription stimulant use but other studies have found that older students and postgraduates are more likely to be users of prescription stimulants [17]. This would be a useful avenue of inquiry for further research in Australia.

\section{Conclusion}

Further studies are needed to confirm the low prevalence of prescription stimulant use to improve academic performance among Australian students and to confirm the factors associated with such use. Until further evidence suggests otherwise there does not appear to be a strong case for specific policies or interventions targeting risky prescription stimulant use for improving academic performance among Australian students.

\section{Abbreviation \\ (ADHD): Attention Deficit Hyperactivity Disorder}

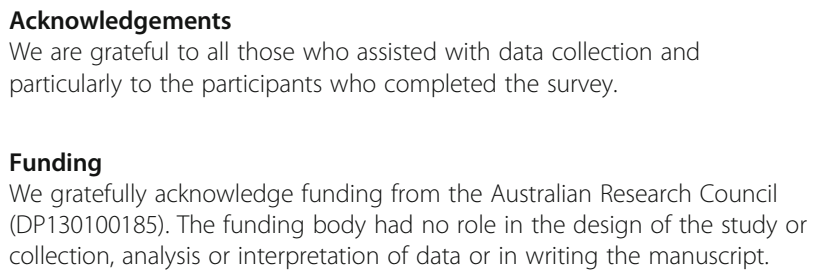

Availability of data and materials

The datasets used and/or analysed during the current study are available from the corresponding author on reasonable request. 


\section{Authors' contributions}

All authors made significant contributions to the conception and design of this study. CJ and GC analysed the data and JL drafted the manuscript. All authors made significant contributions to the writing of the manuscript. All authors critically reviewed and approved the final manuscript.

\section{Ethics approval and consent to participate}

Written informed consent was obtained from all individual participants included in the study and participation in the study was voluntary. This study was approved by the University of Queensland Behavioural and Social Sciences Ethical Review Committee (Approval Number: 2014001403) and permission was also granted for data collection at each participating university.

\section{Consent for publication}

Not applicable.

\section{Competing interests}

The authors declare that they have no competing interests.

\section{Publisher's Note}

Springer Nature remains neutral with regard to jurisdictional claims in published maps and institutional affiliations.

\section{Author details}

'Australian Research Centre in Sex, Health and Society, School of Psychology and Public Health, College of Science, Health and Engineering, Building NR6, La Trobe University, Bundoora, VIC 3086, Australia. ${ }^{2}$ School of Public Health, The University of Queensland, Herston, Brisbane, QLD, Australia. ${ }^{3}$ The University of Queensland Centre for Youth Substance Abuse Research, St Lucia, Brisbane, QLD, Australia. ${ }^{4}$ School of Health and Social Development, Deakin University, Geelong, Australia. ${ }^{5}$ National Drug and Alcohol Research Centre, University of New South Wales, Sydney, NSW, Australia. ${ }^{6}$ Sydney Health Ethics, University of Sydney, Sydney, NSW, Australia. ${ }^{7}$ Research Development Unit, Caboolture Hospital, Caboolture, QLD, Australia. ${ }^{8}$ School of Clinical Medicine, Prince Charles Hospital Northside Clinical Unit, The University of Queensland, Brisbane, QLD, Australia. ${ }^{9}$ Pragmatic Health Ethics Research Unit, Institut de recherches cliniques de Montréal, Montréal, Quebec, Canada.

Received: 26 June 2018 Accepted: 8 November 2018

\section{Published online: 19 November 2018}

\section{References}

1. Kaye S, Darke $S$. The diversion and misuse of pharmaceutical stimulants: what do we know and why should we care? Addiction. 2012;107(3):467-77.

2. Jensen C, Forlini C, Partridge B, Hall W. Australian university students' coping strategies and use of pharmaceutical stimulants as cognitive enhancers. Front Psychol. 2016;7:277

3. Mazanov J, Dunn M, Connor J, Fielding M-L. Substance use to enhance academic performance among Australian university students. Perform Enhanc Health. 2013;2(3):110-8.

4. Partridge B, Bell S, Lucke J, Hall W. Australian university students' attitudes towards the use of prescription stimulants as cognitive enhancers: perceived patterns of use, efficacy and safety. Drug Alcohol Rev. 2013;32(3): 295-302.

5. Bell S, Partridge B, Lucke J, Hall W. Australian university students' attitudes towards the acceptability and regulation of pharmaceuticals to improve academic performance. Neuroethics. 2013;6(1):197-205.

6. Lucke J, Partridge B. Towards a smart population: a public health framework for cognitive enhancement. Neuroethics. 2013;6(2):419-27.

7. Compton WM, Han B, Blanco C, Johnson K, Jones CM. Prevalence and correlates of prescription stimulant use, misuse, use disorders, and motivations for misuse among adults in the United States. Am J Psychiatry. 2018. https://doi.org/10.1176/appi.ajp.2018.17091048.

8. Hulme S, Bright S, Nielsen S. The source and diversion of pharmaceutica drugs for non-medical use: a systematic review and meta-analysis. Drug Alcohol Depend. 2018;186(1):242-56.

9. Ford J, Pomykacz C. Non-medical use of prescription stimulants: a comparison of college students and their same-age peers who do not attend college. J Psychoactive Drugs. 2016;48(4):253-60.
10. Weyandt L, Marraccini M, Gudmundsdottir B, Zavras B, Turcotte J, Munro B, et al. Misuse of prescription stimulants among college students: a review of the literature and implications for morphological and cognitive effects on brain functioning. Exp Clin Psychopharmacol. 2013;21(5):385.

11. Benson K, Flory K, Humphreys K, Lee S. Misuse of stimulant medication among college students: a comprehensive review and meta-analysis. Clin Child Fam Psychol Rev. 2015;18(1):50-76.

12. Arria AM, Wilcox HC, Caldeira KM, Vincent KB, Garnier-Dykstra LM, O'Grady KE. Dispelling the myth of 'smart drugs': cannabis and alcohol use problems predict nonmedical use of prescription stimulants for studying. Addict Behav. 2013:38:1643-50

13. McCabe S, Knight J, Teter $\mathrm{C}$, Wechsler $\mathrm{H}$. Non-medical use of prescription stimulants among US college students: prevalence and correlates from a national survey. Addiction. 2005;100(1):96-106.

14. McCabe S. Misperceptions of non-medical prescription drug use: a web survey of college students. Addict Behav. 2008;33(5):713-24.

15. Teter C, McCabe S, LaGrange K, Cranford J, Boyd C. Illicit use of specific prescription stimulants among college students: prevalence, motives, and routes of administration. Pharmacotherapy. 2006;26(10):1501-10.

16. Bogle K, Smith B. Illicit methylphenidate use: a review of prevalence, availability, pharmacology, and consequences. Curr Drug Abuse Rev. 2009; 2(2):157-76

17. Singh I, Bard I, Jackson J. Robust resilience and substantial interest: a survey of pharmacological cognitive enhancement among university students in the UK and Ireland. PLoS One. 2014;9:e105969.

18. Gudmundsdottir B, Weyandt L, Ernudottir G. Prescription stimulant misuse and ADHD symptomatology among college students in Iceland. J Atten Disord. 2016. https://doi.org/10.1177/1087054716684379.

19. Betancourt J, Ríos J, Pagán I, Fabian C, González A, Cruz S, et al. Non-medical use of prescription drugs and its association with socio-demographic characteristics, dietary pattern, and perceived academic load and stress in college students in Puerto Rico. P R Health Sci J. 2013;32(2):89-94.

20. Messina BG, Silvestri MM, Kiulio AR, Murphy JG, Garza KB, Correia CJ. Alcohol use, impulsivity, and the non-medical use of prescription stimulants among college students. Addict Behav. 2014:39(12):1798-803.

21. Stafford J, Breen C. Australian trends in ecstasy and related drug markets 2016. Findings from the ecstasy and related drugs reporting system (EDRS). Australian drug trends series Sydney, National Drug and Alcohol Research Centre. No 172. 2017.

22. Green R, Moore D. 'Kiddie drugs' and controlled pleasure: recreational use of dexamphetamine in a social network of young Australians. Int J Drug Pol. 2009;20(5):402-8.

23. Clemow D, Walker D. The potential for misuse and abuse of medications in ADHD: a review. Postgrad Med. 2014;126(5):64-81.

24. Bavarian N, McMullen J, Flay B, Kodama C, Martin M, Saltz R. A mixedmethods approach examining illicit prescription stimulant use: findings from a northern California university. J Prim Prev. 2017;38(4):363-83.

25. Cruz S, Sumstine S, Mendez J, Bavarian N. Health-compromising practices of undergraduate college students: examining racial/ethnic and gender differences in characteristics of prescription stimulant misuse. Addict Behav. 2017;68:59-65.

26. The Social Research Centre. 2016 Student Experience Survey National Report. https://www.qilt.edu.au/about-this-site/student-experience. Quality Indicators for Learning and Teaching, 2017. Funded by the Australian Government Department of Education and Training. Accessed 28 April 2018.

27. Arria A, Caldeira K, Vincent K, O'Grady K, Cimini M, Geisner I, et al. Do college students improve their grades by using prescription stimulants nonmedically? Addict Behav. 2017;65:245-9.

28. Partridge B, Bell S, Lucke J, Yeates S, Hall W. Smart drugs "as common as coffee": media hype about neuroenhancement. PLoS One. 2011;6(11):e28416.

29. Lucke JC, Bell S, Partridge B, Hall WD. Deflating the neuroenhancement bubble. AJOB Neurosci. 2011;2(4):38-43. 